\title{
Competitors and Cooperators: A Micro-Level Analysis of Regional Economic Development Collaboration Networks
}

\section{Predispositions and orientation toward cooperation} or competition with other jurisdictions can play a critical role in implementing regional collaboration. By examining collaboration at the micro level, this article investigates how individual factors, including perceptions of cooperation and competition, as well as institutional and environmental factors, are related to regional collaboration. In particular, the authors assert that competitive motivation may support the emergence of regional governance mechanisms. This article explores the relationships between competitive/cooperative motivations and interlocal collaboration networks based on a network survey conducted in the Orlando, Florida, metropolitan area. The authors apply a quadratic assignment procedure regression analysis to examine how dyadic conceptual ties of cooperation and competition, along with the effect of community characteristics, affect policy network structures for economic development. By comparing estimated coefficients with sampling distributions of coefficients from all of the permuted data sets, the regression results indicate the influences of perceived competition/cooperation on the network exchange.

$\mathrm{T}$ he local economic development policy arena often is described as highly competitive because local governments often pursue their individual opportunities to promote business and expand their own jurisdiction's tax base. Economic development is primarily a local responsibility, with assistance from state and federal agencies (Gordon 2007; Peterson 1981). The inherently competitive nature of local government development agendas,

[D]iverse values and perceptions about other jurisdictions can shape interlocal behaviors among communities and, thus, the overall configuration of regional governance systems.
Collaborative efforts can address important issues such as economies of scale, spillovers, urban sprawl, environmental impacts, income disparity, duplication of policies and services, and so on (Feiock 2002; Fleischmann 2000; Goetz and Kayser 1993). In fact, over several decades, local governments in many regions of the United States have established various types of collaborative development strategies that take a regional approach to policy formation and implementation in order to enhance their regional economic development. In other words, some communities operate as boundary spanners by promoting economic development through horizontal as well as vertical collaboration (Agranoff and McGuire 2003).

Regional governance strategies, however, can be employed successfully only when competitive perceptions and motivations are overcome (Gordon 2007). Collaborative efforts among local governments may be hampered by their desires to maintain local autonomy, distrust among local jurisdictions, conflicting interests among potential participants, or an imbalance in powers and resource endowments (Visser 2002). On the other hand, even among fierce competitors, there is pressure for local jurisdictions not to be isolated from various types of potential collaborative activities that might bestow significant advantages. This suggests that diverse values and perceptions about other jurisdictions can shape interlocal behaviors among communities and, thus, the overall configuration of regional governance systems.

Interlocal collaboration occurs when two or more local governments seek to accomplish a in combination with jurisdictional fragmentation, produces complexity and uncertainty for potential coordination and collaboration efforts. However, positive and negative intergovernmental externalities that result from economic development create demands for more integrated solutions. desirable outcome through coordination or cooperation. Collective action begins with the recognition of interdependency among local governments in which a decision or action of one government affects the actions of others. This strategic interaction among actors becomes more complicated and uncertain as the
In-Won Lee is assistant professor in the Department of Public Administration at Dankook University. His research focuses on urban management and policy, local public finance, collaborative governance, energy and sustainable growth policy, and interorganizational and intersectoral management. His work has appeared in Urban Affairs Review, Policy Studies Journal, Internal Review of Public Administration, and other journals.

E-mail: in1lee04@dankook.ac.kr

Richard C. Feiock is Augustus B. Turnbull Professor of Public Administration at Florida State University. His books include City-County Consolidation and Its Alternatives (M. E. Sharpe, 2004), Metropolitan Governance: Conflict, Competition, and Cooperation (Georgetown University Press, 2004), and Self-Organizing Federalism (Cambridge University Press, 2009). His current work is supported by the National Science Foundation and the Lincoln Institute for Land Policy.

E-mail: rfeiock@fsu.edu

Youngmi Lee (corresponding author) is postdoctoral research fellow in the Graham Environmental Sustainability Institute at the University of Michigan in Ann Arbor. Her research interests are local economic development policy, network management and leadership, collaborative governance, and social network analysis. E-mail: korea0406@gmail.com

Public Administration Review Vol. 72, Iss. 2, pp. 253-262. (@ 2011 by The American Society for Public Administration. DOI: 10.111/j.1540-6210.2011.02501.x. 
number of local jurisdictions increases, particularly in metropolitan areas. Collective action problems occur when local governments, which are attempting to maximize their own welfare, do not pursue collective benefits for the entire region, which eventually leads to an inferior outcome (Feiock and Scholz 2010).

The alternative governance mechanisms that are available to local government units include centralized authority, mutually binding contracts or agreements, and network embeddedness (Feiock 2004, 2009). This research generally focuses on the role of network embeddedness, which is the most pervasive but the least understood of these mechanisms. By relying on social, economic, and political relationships rather than formal authority, network embeddedness offers flexibility for rules, procedures, and exchanges to be decided locally while preserving the autonomy of the actors involved.

Economic development is an ideal policy arena for examining how the perceptions and motivations of local officials ultimately determine overall patterns of collaborative arrangements. The dilemma for local actors working on economic development is that cooperation with other jurisdictions provides tremendous potential benefits once it turns out to be successful, but it also poses greater risks than cooperation in most other areas (Lee, Feiock, and Park 2011). This suggests that local government leaders' predispositions and orientation toward cooperation or competition with other jurisdictions play critical roles in implementing regional collaborative arrangements. However, extant research in public administration pays little attention to how local leaders' perceptions of competitive or collaborative environments relate to their interlocal policy network relationships. In contrast, this article provides a micro-level examination of how individual factors, including perceptions of cooperation and competition, as well as institutional and environmental factors are related to regional collaboration.

The literatures on interlocal policy networks tend to focus exclusively on cooperation as a motivation for informal policy networks, and thus they fail to systematically capture how competitive as well as cooperative environments might foster the creation of regional governance mechanisms. This article explores the relationships between competitive/cooperative motivations and policy communication through informal policy networks among local governments using a network survey conducted in the Orlando, Florida, metropoli$\tan$ area. The construction of dyadic data on the local government relationships allows us to investigate how competitive and cooperative development environments influence the structure of informal policy networks.

\section{Informal Policy Networks as a Regional Governance Mechanism}

While decentralized decision making can generate collaborative regional solutions, it also might lead to noncooperation and destructive competition for development. In this sense, these collaborative regional efforts can be implemented successfully only if competitive perceptions and motivations are overcome (Gordon 2007;
Olberding 2002). Institutional arrangements play an important role in making collaboration attractive by providing specific rules about how the negotiation and bargaining process for collective outcomes should be organized, how different incidences and responsibilities should be allocated among participants, and how agreed-upon rules will be implemented and enforced (Steinacker 2004). In this sense, regional governance can be recognized as resolving collective action problems; setting constraints that help participating governments avoid the negative effects of collective actions such as diseconomies of scale, urban sprawl, environmental impact, income disparity, and duplication of policies; enabling local governments to interact collectively to create beneficial outcomes; and reconciling rationality at the individual level with rationality at the collective level (Andrew 2009).

One virtue of various regional governance mechanisms is that they allow participating actors to achieve their common goals in a selforganizing manner. It usually requires negotiation to reach consensus, and this process, in turn, provides an opportunity to develop trust and reciprocal arrangements among members that is critical for reducing the costs of reaching and maintaining an agreement. We refer to the patterns of informal relationships that preserve full local autonomy and require no formal authority as "informal policy networks." These relationships, which are embedded in socioeconomic and political relationships, can provide critical support for monitoring, enforcement, and compliance with the self-developed institutional rules that impose constraints on the autonomy of participants (Feiock and Scholz 2010; Schneider et al. 2003). The process of creating and amending their own rules generates greater legitimacy among participants, who can design levels of flexibility and enforcement that are appropriate for the concerns of the participants. One successful self-organizing effort can cultivate mutual reciprocity, trust, and collaborative norms in the regional arena (Feiock et al. 2010). This process, in turn, increases the likelihood of further efforts that can resolve other types of regional problems.

Collaborative networks are an outcome of purposive activities to forge relationships in order to solve problems by creating or discovering solutions within a given set of constraints, including knowledge, time, resources, and even competition (Agranoff and McGuire 2003; Schrage 1995). For example, from their case studies, Agranoff and McGuire (2003) found that collaborative economic development networks emerge as a dominant process of facilitating and operating in multiorganizational arrangements to solve problems that cannot be solved, or solved easily, by single organizations. Through this process, multiple governmental and nongovernmental entities jointly steer courses of action and generate policy outcomes that enhance the overall welfare of their communities (Agranoff and McGuire 2003). In fact, this collaborative network has been proven to play a significant role in improving individual policy outcomes by mitigating collective action problems as well as capturing a greater advantage from collaborative problem solving (Agranoff and McGuire 2003; Lubell et al. 2002; Meier and O'Toole 2002; Provan and Milward 2001). 


\section{Network Embeddedness and Perceptions toward Competition and Cooperation}

Policy networks are one of several alternative governance mechanisms for regional economic development. Like other regional institutions, networks reduce transaction costs and uncertainty by defining and regulating participants' behaviors and expectations. On the other hand, unlike less adaptive and more formal alternatives, network embeddedness relies more on voluntary agreements among local units that are coordinated and enforced through social, economic, and political relationships rather than authority (Feiock 2009).

In this sense, self-organizing policy networks offer several potential advantages over more formal solutions. By allowing more local autonomy, network embeddedness helps local units overcome individual governments' reluctance to delegate their autonomy to newly established arrangements and minimizes political conflicts involved in revoking existing authority from local governments. By generally requiring the consent of all members, self-governing institutions enhance the search for a mutually advantageous resolution of collective action dilemma, and they reduce potential conflicts involved when majorities can impose solutions on unwilling minorities (Feiock et al. 2010). Because they emerge from planned and unplanned interactions among local actors, policy network structures ensure sufficient flexibility for rules, procedures, and exchanges to be decided locally. Therefore, the perceptions and motivations of local actors toward collaborative efforts play an especially important role in establishing and maintaining network interactions with neighboring jurisdictions.

How, then, do local governments perceive other government units in relation to their economic development, especially in terms of competition or cooperation? Goetz and Kayser (1993) found that 85 percent of municipalities surveyed in the Twin Cities in Minnesota felt that competition exists, but only half of them viewed this competition as beneficial. Although this dilemma may be solved by collectively adopting regional economic development strategies, such efforts often are destined to fail because of unequal needs, unequal resources, and inequities in power and accountability (Nice 1987). In this regard, critics believe that interlocal competition is a permanent feature of metropolitan regions. However, interlocal competition also may foster mutual admiration and respect among competitors (Gordon 2007), and it even may produce a willingness to learn from each other (Smith and Beazley 2000). In addition to being competent and aware of how and where to obtain needed resources, local governments are required to take great care not to exploit or betray purpose and to demonstrate respect and fairness to their collaborative partners (Ferguson and Stoutland 1999). Therefore, differences may be lessened out of mutual understanding, which, in turn, mitigates the inevitable problems of collective actions such as distrust, conflicting interests, and unequal powers among potential partners.

In addition to mutual admiration, there are strategic incentives for local jurisdictions to keep track of their competitors' activities. When local officials are politically risk averse (Lee, Feiock, and Park 2011; Steinacker 2004), the cost of being left behind will exceed the loss of not sharing information with their competitors. Being isolated from various ongoing activities among neighboring jurisdictions might place local officials in a politically risky position, especially when citizens expect them to produce tangible outcomes. In the context of economic development, local officials can benefit from collecting information, benchmarking, and participating in joint activities that are visible to local citizens. This suggests that no matter what motivations are involved, either admiration or political risk aversion, forging informal relationships with other competitive actors to share and gather information is a critical element of managing local economic development.

Moving from the competitive to the cooperative policy environment, we find that generating formal or informal links with potential partners is even more important. Repeated interactions in one or more policy arenas are manifestations of networked relationships that help control uncertainties and overcome collective action problems (Granovetter 1985; Gulati and Gargiulo 1999; Lubell et al. 2002). Because information about actors, especially regarding previous decisions and behaviors, is relatively open to network participants, economic development policy network structure reduces the possibility of breaking the trust that has been established among participants. In addition, the structure provides an extensive monitoring mechanism and facilitates mutual reciprocity, trust, and conformance to the rules of the game (Coleman 1988). Therefore, consideration of reputation, communication, trust, and social norms imposes constraints on defection and opportunism that increase the stability of a regional governance structure (Feiock, Steinacker, and Park 2009).

Moreover, networked relationships help resolve many issues with regard to arranging the details of collaborative efforts among cooperative partners. In other words, differences in demands and resource endowments, imbalances in power, and disagreements resulting from conflicting interests among participants can be lessened through an environment that is conducive to cooperation, which eventually mitigates the inevitable problems of collective action among potential partners (Fleischmann 2000; Visser 2002). Therefore, network embeddedness mitigates distrust in competitive environments, and it also counters negative predispositions to enhance local officials' willingness to learn and teach, thus allowing for future cooperation on other policy issue arenas. In addition, where there is more trust, there is less need to constantly monitor compliance (Alter and Hage 1993). In the long run, these positive aspects of cooperative environments fortify network embeddedness among members. In this sense, social capital is a critical factor for economic development at any level that helps formulate new strategies for growth and development (Garcia 2006). Social capital fostered by local interactions through network embeddedness encourages commitments and reinforces a norm of reciprocity that facilitates regional cooperation (Coleman 1988; Putnam 1995).

Therefore, perceptions about other communities and policy networks generally make local governments willing to forge relationships not only with their cooperative partners, but also with existing 


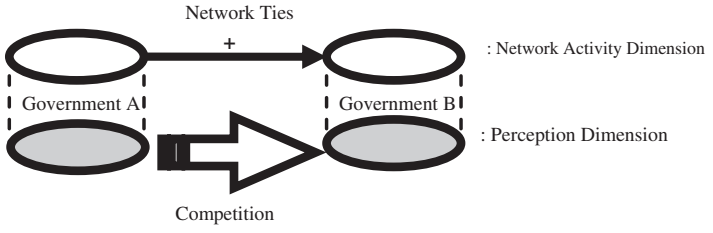

(a) Perceived Competition and Policy Networks

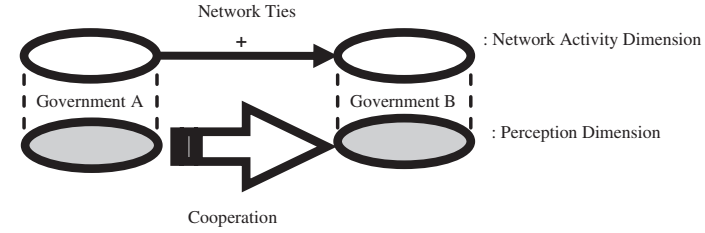

(b) Perceived Cooperation and Policy Networks

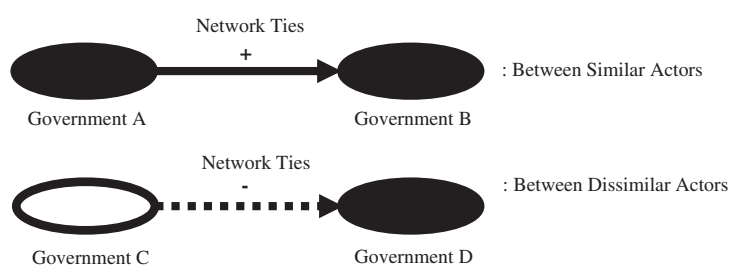

(c) Theory of Homophily

Figure 1 Relationship between Perceptions and Policy Networks

competitors. However, their underlying motivations to form linkages will differ: competitive motivations, along with mutual recognition of competitors' strengths and abilities, lead to a desire to be informed about what other jurisdictions are pursuing and to utilize potential opportunities to collect information, benchmark, and participate in some collaborative efforts in order to be less isolated. In contrast, the motivations for cooperation tend to create links with others in order to address perceived obstacles to collaboration and implement collaborative strategies once they are agreed upon.

\section{Hypotheses}

We expect that local governments are willing to forge relationships not only with their potential cooperative partners, but also with their eminent competitors, and that their underlying motivations to forge policy networks will be different. (see Figure 1)

$\mathbf{H}_{1}$ (perceived competition and policy networks): In highly competitive environments, in which a local government's development strategies are designed to be competitive, there is a tendency for the local officials to establish linkages with their competitors.

As a local government recognizes its competition to be tougher, the more likely it is to forge a cooperative link with the competitor, while at the same time continuing to compete. The motivation for joint efforts is driven by the local officials' desires to have information about what other jurisdictions are pursuing and to avoid being isolated from other potential opportunities from collaborative efforts. This motivation sometimes is fortified by mutual admiration and respect and even a willingness to learn from their most eminent competitors.

$\mathbf{H}_{2}$ (perceived cooperation and policy networks): In a more cooperative environment, in which a local government's strategies are designed to be more cooperative with other jurisdictions, there is a tendency for the local official to establish linkages with potential cooperators.

The motivation is driven by the need to mitigate the inevitable problems of collective action and to facilitate collaborative efforts among potential partners. Cooperative strategies address perceived obstacles to collaboration and the implementation of collaborative strategies once they are agreed upon by each of the governments involved.

$\mathbf{H}_{3}$ (theory of homophily): Actors who share similar socioeconomic attributes and political institutions are more likely to create linkages with each other because they are more likely to share similar economic development agendas and policy preferences, which reduces information costs and predisposes actors to cooperate.

\section{Data and Methods}

To test the relationship between predispositions and orientations toward competition/cooperation and the emergence of policy networks for economic development, we employ quadratic assignment procedure (QAP) analysis. We examine how the perceptions of competitive or collaborative relationships with other governments influence the tendency to establish informal policy communication networks in the area of economic development. This section describes the data and methods used to address this research question.

First, based on the dyadic information collected on each category of perceptions and informal networks, the QAP correlation analysis is employed to investigate the simple correlation between competition/cooperation matrices and the policy network matrix (see table 1). Second, the QAP regression analysis examines how the two contrasting motivations, along with similarities or differences in some community attributes, affect the structures of policy networks for economic development (see table 2). While interpretations and implications of these analyses may be very similar to a traditional statistical approach, the major difference is that the QAP analyses deal with a series of dyadic data in which observations are more likely to be interdependent. The QAP techniques allow us to control for interdependencies that are common in social network data. ${ }^{1}$

While there are limitations when surveying organizations in a single metropolitan area, this method has the advantage of allowing us to control for state and regional variations. The Kissimmee-Orlando 
Table 1 Descriptive Statistics: Dyads between Local Governments on Each Dimension (Policy Networks, Competition, and Cooperation)

\begin{tabular}{lclcc}
\hline & $\begin{array}{c}\text { Policy } \\
\text { Networks }\end{array}$ & & Competition & Cooperation \\
\hline Dyadic counts & 465 & Dyadic counts & 465 & 465 \\
Mutual & 42 & Mutual & 13 & 23 \\
Asymmetric & 108 & Asymmetric & 122 & 138 \\
Null & 315 & Null & 330 & 304 \\
Network density & 0.2065 & Matrix density & 0.356 & 0.490 \\
Average degree & 6.1935 & Average strength & 4.774 & 5.936 \\
\hline
\end{tabular}

Table 2 Descriptive Statistics: Actor Attributes: Total of 31 Local Governments

\begin{tabular}{lccc}
\hline & Min & Max & Mean \\
\hline Population & 19 & $1,043,500$ & 87,296 \\
Median income & 25,988 & 88,809 & 44,298 \\
Race (Non-Hispanic white ratio) & 43.7 & 95.7 & 72 \\
County & 0 & 3 & 1.16 \\
Form of government & 0 & 1 & 0.81 \\
\hline
\end{tabular}

metropolitan area was selected because it is one of the fastestgrowing urban regions in the United States and has a highly fragmented system of general-purpose local governments. The local governments in the metropolitan area demonstrate substantial variance in their size and other socioeconomic attributes. While localities tend to pursue their own strategies for development (e.g., providing tax incentives and issuing development bonds within their own jurisdictions), they also have a history of collaborative efforts (e.g., marketing and promoting their localities, joint operation of business assistance programs, establishing joint ventures or partnerships, and developing joint strategic planning).

The network setting consists of 27 cities and four counties in the Kissimmee-Orlando metropolitan area. A total of 38 city and county governments in the four-county (Lake, Orange, Osceola, and Seminole) metropolitan area were surveyed in 2006-2007, and 81.5 percent of the jurisdictions responded to our surveys (31 out of 38).

The survey asked key respondents — mostly city managers or the top economic development officials_-in each of these governments to report on several issues: (1) the extent to which the development strategies of a responding local government reflect competition with each of the governments listed in the survey instrument (competition matrix), ${ }^{2}$ (2) the extent to which the development strategies of a responding local government reflect cooperation with each of the governments listed in the survey instrument (cooperation matrix), ${ }^{3}$ and (3) which governments a responding local government had interacted with (including discussion, advice, and information sharing) on economic development issues in the previous year (informal network matrix) and how often. The specific questions in both the competition and cooperation matrices were designed to measure the intensity of the predisposition of competition or cooperation toward other specific local governments. The ordinal scale ranges from 0 (not at all) to 4 (great extent).

The informal policy communication network matrix is based on a question that asked the frequency of contacts among pairs of actors and collapsed the frequency into a dichotomous variable that was coded 0 if there was no interaction and 1 if there was annual or more frequent (e.g., monthly, weekly, or daily) contact. ${ }^{4}$ Although network contacts can occur on several different dimensions (e.g., discussion, information sharing, advice), we asked respondents to report a more general aspect of network contacts. Thus, we were able to collect information on the level of network activities in a single dimension (informal communication network).

The information gathered was used to construct three separate matrices capturing both perceptions of local officials toward policy competition/cooperation and the existence of informal networks for economic development. Consistent with the network analysis, we converted our data into a 31 x 31 matrix. For the perception matrices (competition/cooperation), we kept the original scale of measure (0-4); however, the network contact matrix was collapsed to a binary variable that was coded 0 if there was no interaction and 1 if there was annual or more frequent interaction. In other words, only 0 (no interaction) was coded as 0 , and all other responses (1-5, ranging from annual interaction to daily interaction) were coded as $1 .{ }^{5}$ Based on these criteria, we translated the network contact information into an adjacency matrix of links for each of the participating actors, where 1 represents existing interactions and 0 denotes the absence of interaction. Because the values in the matrix reflect each government's evaluation of the relationship between two governments with respect to either perceptions or activity, the adjacency matrices are asymmetrical in their structure. This operation allows us to investigate the correlations across three separate matrices in the later analyses.

We also include the characteristics of communities in the QAP multiple regression analysis in order to test whether similarities or differences between two actors increase network links between them. These include socioeconomic attributes (e.g., population size, median household income, ratio of non-Hispanic white population), political institutions (e.g., whether municipalities belong to same the county and whether they maintain the same local form of government), and geographic proximity. The data on actor attributes were collected from the archival source of the local jurisdiction in the Kissimmee-Orlando metropolitan area. Then, the data for each variable were constructed in separate matrices in which each cell in the matrix represents the difference between two matching governments. For example, if government A has 100,000 residents and government $\mathrm{B}$ has 60,000 residents, the row $\mathrm{A}$ of column $\mathrm{B}$ has a value of 40,000 . For the binary and categorical variable, we assign 1 if both governments belong to the same categories and 0 otherwise. For instance, if government $\mathrm{C}$ belongs to Orange County and government $\mathrm{D}$ is in Seminole County, row $\mathrm{C}$ of column $\mathrm{D}$ has a value of 0 .

\section{Quadratic Assignment Procedure Analysis}

To investigate the extent to which each motivation-competitive or cooperative-is associated with the probability of informal policy networks being formed, we first utilized the matrix correlation analysis in the UCINET program. The analysis employs quadratic assignment procedures analysis to identify the degree of association between matrices and develop standard errors to test for its significance (Hanneman and Riddle 2005). By performing random permutation (simulation) on the rows and columns of the two matrices, QAP estimates the measure of association when there is no 
systematic connection between the two relations. In doing so, the QAP analysis takes into account the assumption of independency of observations in standard bivariate and multivariate analyses (Shrestha and Feiock 2009). ${ }^{6}$ This QAP correlation analysis simply investigates correlation between competition/cooperation matrices and the policy network matrix.

We supplement this analysis by estimating the QAP matrix regressions in the UCINET program to examine how competition and cooperation, along with the effect of community characteristics, influence the structures of the policy network in the area of economic development. By comparing the estimated coefficient with the sampling distribution of coefficients from all the permuted data sets, the regression results essentially indicate whether there is a significant presence of stimulating mechanisms between the perceived competition/cooperation and network exchanges for economic development between pairs of local governments. For example, if a cooperative environment is perceived between two local jurisdictions in the cooperation matrix, the estimated coefficient on the perceived cooperation reports the likelihood that an informal network for economic development also exists between them.

\section{Results}

Figure S2 shows the policy network structures among local governments in the Orlando metropolitan area. (Figures S2-S4 can be found in the online version of this article.) Each node represents local governments in this metropolitan area, and each link indicates an interaction with a corresponding actor on economic development issues in forms of discussion, advice, and information sharing. It was created based on the degree centrality scores of each actor using Visone. ${ }^{7}$ This suggests that the more links (i.e., more relationships) an actor has, as indicated by a higher degree centrality, the more central the actors' position in the network is. This is indicated by the placement of the node in this visualization.

Among the various factors that contribute to the policy network structure depicted in figure S2, we contend that perceptions of whether other actors are competitors or cooperators for economic development are crucial. The next two figures reveal how these perceptions are associated with policy networks. In other words, these figures show the extent to which the policy networks result from the perception toward others regarding competition and cooperation.

Figures S3 and S4 depict the relationships between perceptions and policy network structures among local governments through network visualization. A casual observation of the network structure suggests that the perceptions of competition and cooperation are closely related to the existence of the policy network. Clearly, there is strong correlation between perceptions of competition and policy networks, as indicated by the substantial overlap between the two relations, which is represented by purple lines in figure S3. Likewise, the substantial overlap between the perception of cooperation and the policy network indicates that there is a strong correlation between the two relations in figure S4. It is also notable that figure S4 has slightly more overlapping relationships (purple lines) between perception and informal policy networks than figure S3.

The results of the QAP matrix correlation analyses confirm more formally the relationship between the perceived competition/
Table 3 QAP Matrix Correlation (Perceived Competition versus Policy Networks)

\begin{tabular}{lccrc}
\hline Statistics & Value & Significance & Average & Std. Dev. \\
\hline Pearson correlation & $0.213^{* *}$ & 0.027 & -0.001 & 0.090 \\
Simple matching & $0.724^{* *}$ & 0.006 & 0.675 & 0.021 \\
Jaccard coefficient & $0.273^{* *}$ & 0.002 & 0.100 & 0.044 \\
Goodman-Kruskal gamma & $0.689^{* *}$ & 0.002 & -0.034 & 0.282 \\
Hamming distance & $257.000^{* *}$ & 0.006 & 301.531 & 16.544 \\
\hline
\end{tabular}

Notes: A total of 2500 times of permutations are conducted; Hubert's gamma in this analysis is 142.000

Table 4 QAP Matrix Correlation (Perceived Cooperation versus Policy Networks)

\begin{tabular}{lrcrc}
\hline Statistics & \multicolumn{1}{c}{ Value } & Significance & Average & Std. Dev. \\
\hline Pearson correlation & $0.560^{* * *}$ & 0.000 & -0.003 & 0.081 \\
Simple matching & $0.735^{* * *}$ & 0.000 & 0.643 & 0.023 \\
Jaccard coefficient & $0.461^{* * *}$ & 0.000 & 0.114 & 0.043 \\
Goodman-Kruskal gamma & $0.885^{* * *}$ & 0.000 & -0.032 & 0.257 \\
Hamming distance & 244.000*** & 0.000 & 328.578 & 18.862 \\
\hline
\end{tabular}

Notes: A total of 2500 times of permutations are conducted; Hubert's gamma in this analysis is 319.000 .

cooperation matrix and the informal policy network. The estimated measures of association are reported in tables 3 and 4. The second columns in tables 3 and 4 report the values of each measure for the correlation. Because one of the matrices for comparison includes binary data (policy networks) and the other is in an ordinal scale (competition/cooperation matrix), we pay special attention to the interpretation of the values for simple matching and the GoodmanKruskal gamma (Hanneman and Riddle 2005).8 "Significance" in the third columns in tables 3 and 4 tests the significance of the values in column 2 based on standard errors. In addition, "average" in the fourth columns shows the average value of the correlation across a large number of random trials generated by random QAP process (Shrestha and Feiock 2009). In other words, whereas the second column measures a correlation based on observed simple matching, the fourth column shows a correlation from randomly selected matching. The fifth column reports a standard deviation of the distribution of the measures for a correlation across the random trials.

Simple matching coefficients in tables 3 and 4 are 0.724 (perceived competition versus informal networks) and 0.735 (perceived cooperation versus informal networks), respectively. And these values are statistically significant. In other words, when there is a competitive perception between two local governments, there is about a 72 percent chance that this motivation leads to an informal network connection (represented by 1 in the policy network matrix). Likewise, if there is a cooperative perception between two local governments, there is about a 74 percent chance that a network linkage emerges between the two.

Similarly, the values for the Goodman-Kruskal gamma reported in tables 3 and 4 show how the intensity of those perceptions is related to the likelihood of a network linkage being present. ${ }^{9}$ For example, the Goodman-Kruskal gamma (0.689) is smaller than the simple matching coefficients $(0.724)$ in table 3 . This suggests that although perceived competition is associated closely with the presence of network contacts, there might be a negative relationship between intense competition and participation in informal networks for economic development. To the contrary, the Goodman-Kruskal gamma $(0.885)$ is greater than the simple matching coefficients $(0.735)$ in table 4 , which implies that there is a positive association between 
the intensity of perceived cooperation and participation in informal networks for economic development.

Therefore, the results of the QAP matrix correlation analyses generally support the association between perceived competition/cooperation and informal policy networks for economic development. Although perceived cooperation appears to be a stronger factor, all measures of this tendency turn out to be statistically significant.

Next, we estimate the QAP matrix regression analysis to examine whether there is a tendency for competitive/cooperative perceptions to be positively associated with the structures of development policy networks. ${ }^{10}$ Here, we employ three models, from a simpler model to a more extended model: model 1 includes only perceived competition and cooperation as independent variables. Similarly, model 2 examines the impact of perceived competition and cooperation, controlling for geographic proximity of network ties among local jurisdictions. Finally, model 3 investigates how two different perceptions, along with the effect of similarity or dissimilarity in community characteristics, are related to the structures of policy networks in the area of economic development.

Model fits $\left(R^{2}\right)$ for each model are significant at the 0.001 level. ${ }^{11}$ The coefficient for the cooperative perception in model 1 is positive and statistically significant (0.552). This result holds even after controlling for geographic proximity (model 2) and similarities in other community attribute variables (model 3 ). The positive coefficient for the perceived cooperation variable implies that there is a tendency to reinforce network ties among actors when they recognize others as cooperative partners. On the other hand, there is no evidence to suggest that the probability of establishing informal ties is influenced by the officials' perception of their economic development strategies as being competitive. Although the coefficient for the competitive perception is in the predicted direction $(0.021)$, it is not statistically significant. This result also holds throughout the models tested in this analysis. ${ }^{12}$ The results on two key independent variables in this QAP matrix regression analysis might confirm our findings from the QAP matrix correlation analysis that perceived cooperation appears to be a much stronger factor. In other words, the fact that the Goodman-Kruskal gamma (0.689) is smaller than simple matching coefficients (0.724), which suggests that although perceived competition might be closely related to the presence of network contacts, the marginal impact of perceived competition from local government becomes minimal as perceived competition becomes intense, especially when the impact of perceived competition and cooperation are considered together. Therefore, cooperative perception appears to be a more strongly reinforcing mechanism to forge network relationships among potential partners.

In addition, some community attributes were found to be important in model 3. In particular, geographic proximity and similarity in median income are positively associated with network ties. Community median income similarity is likely to result in more links with others because similarity among jurisdictions in their income levels reflects similar economic agendas and policy preferences, which leads to a higher possibility of being potential partners. This particular result supports the homophily argument in the social network literature that similarity (homogeneity) breeds collaboration (Lubell 2007). In addition, race dissimilarity has a negative
Table 5 QAP Multiple Regression Results

\begin{tabular}{|c|c|c|c|}
\hline Variables & Model I & Model II & Model III \\
\hline Perceived competition & 0.021 & 0.021 & 0.013 \\
\hline Perceived cooperation & $0.552 * * *$ & $0.508 * * *$ & $0.458 * * *$ \\
\hline Geographic proximity & & $0.190 * * *$ & 0.067 \\
\hline Population dissimilarity & & & 0.036 \\
\hline Median income dissimilarity & & & $-0.112^{*}$ \\
\hline Race dissimilarity & & & -0.009 \\
\hline Same form of government & & & 0.085 \\
\hline Same county & & & $0.254 * * *$ \\
\hline Intercept & 0.000 & 0.000 & 0.000 \\
\hline$R^{2}$ & $0.313 * * *$ & $0.348 * * *$ & $0.420 * * *$ \\
\hline Adjusted $R^{2}$ & 0.313 & 0.346 & 0.416 \\
\hline Number of observations & 930 & 930 & 930 \\
\hline Number of permutations & 2500 & 2500 & 2500 \\
\hline \multicolumn{4}{|c|}{$\begin{array}{l}\text { Notes: The dependent variable in this analysis is informal policy networks for } \\
\text { economic development; numbers in each variable represent standardized coeffi- } \\
\text { cients; QAP regression in UCINET output does not report standard errors on each } \\
\text { variable but provides } p \text {-values. } \\
\text { Significance: }{ }^{*} p \leq .01 ;{ }^{* *} p \leq .05 ;{ }^{* *}{ }^{*} p \leq .001 \text {. }\end{array}$} \\
\hline
\end{tabular}

coefficient implying that dissimilarity decreases the likelihood of network ties, yet it is not statistically significant. On the other hand, population dissimilarity has a positive association with the observed economic development policy network. This might suggest that because larger city — small city, or central city—suburban city pairs are more likely to possess different types of information and resources, and thus are made better off by sharing complimentary information with each other (Lee, Feiock, and Park 2011). Yet the coefficient on population dissimilarity is not statistically significant, and our conjecture is not confirmed.

Table 5 also reports the constraints of political institutions on the presence of network ties among local governments. Belonging to the same county is positively related to the chance that actors create network relationships. This hypothesis is supported by the QAP regression analysis, which suggests that political institutions provide both constraints and opportunities to local jurisdictions in creating policy network relationships. Communities that had adopted the same form of government also were expected to have cooperative relationships because appointed and elected officials operating under the same institutional arrangements share similar functional objectives and experience (Feiock 2007). Although the relationship is in the predicted direction, it is not statistically significant.

\section{Conclusion}

We seek to understand the conditions under which local governments forge collaborative policy network ties for economic development. Unlike extant research in public administration that focuses primarily on macro-level determinants such as institutional and environmental factors related to collaborative networks among local governments, this article emphasizes micro-level explanations for the emergence of informal networks for economic development. In particular, we are interested in how a community's sense of competition and cooperation with other governments affects its tendency to create collaborative ties with these governments. The central hypothesis that we test is that both strong perceptions of competition and strong perceptions of cooperation produce proactive approaches to collaborate on economic development issues. This suggests that local governments are willing to forge relationships not only with their cooperative partners, but also with existing competitors. However, 
the underlying mechanisms for creating a linkage may be different. Although mechanisms based on cooperative motivation are much studied, competitively motivated mechanisms are intriguing and less well understood.

Local governments are especially likely to perceive themselves in competition with one another in polycentric metropolitan areas (Johnson and Nieman 2004; McGinnis 1999; Ostrom, Tiebout, and Warren 1961). However, this does not necessarily mean that competitive perception always leads to destructive zero-sum environments. Rather, higher levels of individual effort might reflect a situation in which communities share information about best practices in developing regional and local economies (Johnson and Nieman 2004). By applying these strategies, local governments gain valuable information, learn about best practices, and, in some instances, identify opportunities to formally collaborate with one another.

Both QAP correlation and regression analyses reveal several key issues: (1) perceived cooperation is positively and significantly associated with informal networks for economic development, and (2) perceived competition on its own seems to be positively related to informal networks. However, when considered together with perceived cooperation, the influence of competitive motivation weakens. This implies that although perceived competition might be constructively related to the emergence of network ties, the marginal impact of perceived competition from the local government becomes weak as perceived competition becomes intense, especially when the impact of perceived competition and cooperation are considered together.

An empirical analysis reveals that similar jurisdictions, especially in terms of geographic location and economic status, tend to establish informal networks for economic development, which generally supports the theory of homophily. In addition, political institutions prove to be both constraints on and opportunities for local jurisdiction in creating informal networks for economic development.

\section{Discussion}

The findings in this article suggest that even micro-level analysis on interlocal policy networks supports the lessons from the literature on collaboration among local governments. As the empirical analysis in this article indicates and as many eminent scholars have suggested (Agranoff and McGuire 2003; Kettl 1996; Milward 1996; O’Toole 1997), collaborative policy and management networks have become the dominant approach to overcoming the limited resource endowments, and they provide a mechanism that may help multiple players cohere into a workable structure to implement programs, such as trust and the perception of a common purpose (Agranoff and McGuire 2003). In particular, this article suggests that the microlevel predispositions of a local government toward competition and cooperation with others are significant determinants of collaborative activities and, in fact, can be a building block of any interlocal or interorganizational network studies.

This article also has some limitations. First, reliance on survey data from one time point limits our ability to draw conclusions about the causality of the relationship between perceptions and informal networks for economic development. Our data on perceived cooperation/competition and informal networks all come from the same time period and the same survey. While the results of the QAP regression analysis suggest that cooperative and/or competitive motivation leads to the creation of informal networks with other local jurisdiction, it is also plausible that cooperative and/or competitive perceptions of existing policies are the results of informal network activities. Thus, we suggest that future studies should investigate the evolution of networks or the coevolution of networks with perceptions based on longitudinal data that can further advance the understanding of the emergence of collaborative networks.

Second, although perceived cooperation appears to be a stronger factor than perceived competition in the emergence of informal networks from our analyses, we still do not have a systematic understanding about the relationships among competition, cooperative perceptions, and informal networks for economic development. Why is the competitive perception positively and significantly related to the cooperative perceptions? (see note 12). And why, despite this positive relationship, does the influence of competitive motivation on informal networks weaken when it is considered together with perceived cooperation?

In a more empirical sense, two explanations need to be mentioned. First, it is possible that respondents might exaggerate their network activities for collaborative economic development (dependent variables). Although local jurisdictions may experience much greater competitive pressure, they might understate their desire to become a winner when destructive competition is unavoidable, or they might overstate their valuation on collaboration, especially when collaborative strategies are perceived as desirable among peer actors. Second, and conversely, it is also possible that respondents might exaggerate the extent to which localities directly compete with each other. In fact, local governments could exert themselves along different development tracks (Johnson and Nieman 2004). Therefore, localities might, in fact, not be engaged in as much competition with other jurisdictions as often assumed. Rather, they may proceed along multiple tracks, and this leads to much a greater level of interdependency for information and resource exchange (Nieman, Andranovich, and Fernandez 2000). These possibilities provide room for explaining complexity among perceptions toward others and toward network activities. In particular, they provide room to consider the nonlinear relationship between competition and network activity and the interaction between competi-

[T] his article suggests that the micro-level predispositions of a local government toward competition and cooperation with others are significant determinants of collaborative activities and, in fact, can be a building block of any interlocal or interorganizational network studies. tive and cooperative motivations. In this sense, our investigation of the interplay between competitive and cooperative perceptions on collaboration defines an agenda for future work by identifying the key micro-level processes that are involved. In this article, we found that cooperative perception has more of a direct impact on the emergence of network ties. An examination of how competitive motivation mediates this relationship may be the next step in better understanding policy networks as a metropolitan governance mechanism. 


\section{Acknowledgments}

This article was funded by Dankook University and based on work supported by the National Science Foundation under grant SES-0350799.

\section{Notes}

1. The problem with applying the traditional regression approach to social network data is that standard error from regression analysis is misleading. This is because the error terms in the regression are correlated across observations. For example, in our data, a certain jurisdiction has a tendency to give consistently low informal network ratings, so it makes this jurisdiction's residuals become low as well. In other words, observations in the same row or column will be positively correlated, and this makes the standard errors too small and the $p$-values too optimistic (Simpson 2001).

2. The survey asked, "to what extent do development policies of your government reflect competition with each of the government listed below?" This measure ranges from 0 (not at all) to 4 (great extent) in terms of engagement in competition.

3. The survey asked, "to what extent do development policies of your government reflect cooperation with each of the government listed below?" This measure ranges from 0 (not at all) to 4 (great extent) in terms of engagement in cooperation.

4. The specific questions were designed to measure the intensity of network links among jurisdictions ranging from 0 to $5(0=$ no interaction, $1=$ annual interaction, and $5=$ daily interaction).

5. It is notable that our dependent variable (network contacts) cannot be treated as an interval variable because the network frequencies from our survey instruments are not equally spaced. We collapsed this variable into a dichotomous variable (coded 1 for annual or more frequent interaction and 0 otherwise) because we believe that, conceptually, this cut point captures the greatest interval theoretically as well as empirically.

6. What the QAP essentially does is "scramble" the dependent variable matrix through a large number of trials of permutations. By taking the data and scrambling it repeatedly, resulting in multiple random data sets with the dependent variable, multiple analyses can be performed (Simpson 2001).

7. The Visone software is a tool that facilitates the visual exploration of social networks by integrating analysis and visualization of social networks data (see http://visone.info/).

8. The Pearson measure is a reasonable measure when both matrices for comparison have valued relations. The Jaccard coefficient is considered to be a standard measure when dealing with binary relations for both matrices. Finally, Hamming distance is a measure of dissimilarity or distance between the score in one matrix and scores in the other matrix (Hanneman and Riddle 2005).

9. Goodman and Kruskal's gamma statistic is a symmetrical measure for association between variables at the ordinal level. This measure varies from +1 to -1 , based on the difference between concordant pairs and discordant pairs. This provides more flexibility than simple matching by allowing more variation in one or more variables. Goodman and Kruskal's gamma statistic is, in essence, the surplus of concordant pairs over discordant pairs as a percentage of all pairs ignoring ties. This can be given a PRE (proportionate reduction in error) interpretation. For instance, if we ignore tied pairs and guess the ranking of two pairs based on knowledge of the independent (column) variable $x$, then if we are presented with the $x$ values for two randomly selected pairs, we will predict that if the second $x$ is more than the first, then the rank of the second $y$ value will be greater than the rank of the first $y$ value. Therefore, if gamma is .689 , we may interpret that knowing the independent variable (competition/ cooperation in this case) reduces our errors in predicting the rank (not value) of the dependent variable (network ties in this case) by 68.9 percent (Agresti 1996).
10. In this QAP analysis, some of independent variables are highly correlated with one another, such as competition, cooperation, geographic proximity, and so on, which leads to a greater likelihood of multicollinearity problems in regular regression context. By choosing Dekker's semipartialling methods in UCINET, MRQAP analysis provides robust tests for multicollinearity (Dekker, Krackhardt, and Snijders 2003).

11. The $R^{2}$ value in model 1 is modest and low (0.313) but significant at the 0.001 level. In fact, considering the fact that (1) model 1 includes only two key independent variables (competitive and cooperative perceptions), and (2) even a more extended model does not improve the $R^{2}$ value (0.313 to 0.419$)$ substantially, its $R^{2}$ value is moderate and suggests that the perceptions of local government officials toward their neighboring jurisdictions (i.e., competitiveness and cooperativeness) matter in explaining the tendency to form informal ties.

12. This particular finding is attributed to the fact that competition and cooperation are highly correlated, while cooperation is associated more strongly with the presence of policy network. We also run QAP matrix correlation analysis between competition and cooperation matrices to examine how strongly they are related. Their Pearson correlation, simple matching, Jaccard coefficient, and Goodman-Kruskal gamma are $0.348,0.779,0.429$, and 0.888 , respectively. All QAP correlation coefficients are significant at the 0.001 level except Pearson correlation. Pearson correlation is found to be significant at the 0.05 level ( $p$-value is 0.019 ). This consistently suggests that competition and cooperation are highly correlated while each factor influences the presence of policy networks.

\section{References}

Agranoff, Robert, and Michael McGuire. 2003. Collaborative Public Management: New Strategies for Local Governments. Washington, DC: Georgetown University Press.

Agresti, Alan. 1996. Introduction to Categorical Data Analysis. New York: Wiley. Alter, Catherine, and Jerald Hage. 1993. Organizations Working Together. Newbury Park, CA: Sage Publications.

Andrew, Simon. 2009. Regional Integration Through Contracting Networks. Urban Affairs Review 44(3): 378-402.

Coleman, James S. 1988. Social Capital in the Creation of Human Capital. Supplement, American Journal of Sociology 94: 95-120.

Dekker, David, David Krackhardt, and Tom Snijders. 2003. Multicollinearity Robust QAP for Multiple-Regression. Working paper, Computational Analysis of Social and Organizational Systems. http://www.casos.cs.cmu.edu/publications/papers/ dekker_2003_multicollinearity.pdf [accessed November 2, 2011].

Feiock, Richard C. 2002. A Quasi-Market Framework for Local Economic Development Competition. Journal of Urban Affairs 24(2): 123-42.

- 2004. Metropolitan Governance: Conflict, Competition, and Cooperation. Washington, DC: Georgetown University Press.

- 2007. Rational Choice and Regionalism. Journal of Urban Affairs 29(1): 47-63.

. 2009. Metropolitan Governance and Institutional Collective Action. Urban Affairs Review 44(3): 356-77.

Feiock, Richard C., In Won Lee, Hyung Jun Park, and Keon Hyung Lee. 2010. Policy Networks among Local Elected Officials: Information, Commitment, and Risk Aversion. Urban Affairs Review 46(2): 241-62.

Feiock, Richard C., and John Scholz. 2010. Self-Organizing Federalism: Collaborative Mechanisms to Mitigate Institutional Collective Action Dilemmas. New York: Cambridge University Press.

Feiock, Richard C., Annette Steinacker, and Hyung-Jun Park. 2009. Institutional Collective Action and Economic Development Joint Ventures. Public Administration Review 69(2): 257-70.

Ferguson, Ronald F., and Sara E. Stoutland. 1999. Reconceiving the Community Development Field. In Urban Problems and Community Development, edited by Ronald F. Ferguson and William T. Dickens 33-75. Washington, DC: Brookings Institution Press. 
Fleischmann, A. 2000. Regionalism and City-County Consolidation in Small Metro Areas. State and Local Government Review 32(3): 213-26.

García, María Semitiel. 2006. Social Capital, Networks, and Economic Development: An Analysis of Regional Productive Systems. Cheltenham, UK: Edward Elgar.

Goetz, Edward G., and Terrence Kayser.1993. Competition and Cooperation in Economic Development: A Study of the Twin Cities Metropolitan Area. Economic Development Quarterly 7(1): 63-78.

Gordon, Victoria. 2007. Partners or Competitors? Perceptions of Regional Economic Development Cooperation in Illinois. Economic Development Quarterly 21(1): 60-78.

Granovetter, Mark. 1985. Economic Action and Social Structure. Journal of Sociology 91(3): 481-93.

Gulati, Ranjay, and Martin Gargiulo. 1999. Where Do Interorganizationl Networks Come From? American Journal of Sociology 104(5): 1439-93.

Hanneman, Robert A., and Mark Riddle. 2005. Introduction to Social Network Analysis. Riverside: University of California, Riverside. http://www.faculty.ucr. edu/-hanneman/nettext/ [accessed November 2, 2011].

Johnson, Martin, and Max Nieman. 2004. Courting Business: Competition for Economic Development among Cities. In Metropolitan Governance: Conflict, Competition, and Cooperation, edited by Richard C. Feiock, 124-46. Washington, DC: Georgetown University Press.

Kettl, Donald F. 1996. Governing at the Millennium. In Handbook of Public Administration, 2nd ed., edited by James L. Perry, 5-18. San Francisco: Jossey-Bass.

Lee, In Won, Richard C. Feiock, and Hyung Jun Park. 2011. Competition and Cooperative Networks in Local Economic Development: An Exponential Random Graph Analysis. Working paper.

Lubell, Mark. 2007. Familiarity Breeds Trust: Collective Action in a Policy Domain. Journal of Politics 69(1): 237-50.

Lubell, Mark, Mark Schneider, John Scholz, and Mihriye Mete. 2002. Watershed Partnerships and the Emergence of Collective Action Institutions. American Journal of Political Science 46(1): 148-63.

McGinnis, Michael Dean. 1999. Polycentricity and Local Public Economies: Readings from the Workshop in Political Theory and Policy Analysis. Ann Arbor: University of Michigan Press.

Meier, Kenneth J., and Laurence J. O’Toole, Jr. 2002. Public Management and Organizational Performance: The Impact of Managerial Quality. Journal of Policy Analysis and Management 21(4): 629-43.

Milward, H. Brinton. 1996. Symposium on the Hollow State: Control and Performance in Interorganizational Settings. Journal of Public Administration Research and Theory 6(2): 193-95.

Nice, David C. 1987. Federalism: The Politics of Intergovernmental Relations. New York: St. Martin's Press.

Nieman, Max, Gregory Andranovich, and Kenneth Fernandez. 2000. Local Economic Development in Southern California's Suburbs: 1990-1997. San Francisco: Public Policy Institute of California.
Olberding, Julie C. 2002. Does Regionalism Beget Regionalism? The Relationship between Norms and Regional Partnerships for Economic Development. Public Administration Review 62(4): 480-91.

Ostrom, Vincent, Charles Tiebout, and Robert Warren. 1961. The Organization of Government in Metropolitan Areas: A Theoretical Inquiry. American Political Science Review 55(4): 831-42.

O'Toole, Laurence J., Jr. 1997. Treating Networks Seriously: Practical and ResearchBased Agendas in Public Administration. Public Administration Review 57(1): $45-52$.

Peterson, Paul E. 1981. City Limits. Chicago: University of Chicago Press.

Provan, Keith G., and Brinton Milward. 2001. Do Networks Really Work? A Framework for Evaluating Public-Sector Organizational Networks. Public Administration Review 64(4): 414-23.

Schneider, Mark, John Scholz, Mark Lubell, Denisa Mindruta, and Matthew Edwardsen. 2003. Building Consensual Institutions: Networks and the National Estuary Program. American Journal of Political Science 47(1): 143-58.

Schrage, Michael. 1995. No More Teams: Mastering the Dynamics of Creative Collaboration. New York: Currency Doubleday.

Shrestha, Manoj, and Richard C. Feiock. 2009. Governing U.S. Metropolitan Areas: Self-Organizing and Multiplex Service Networks. American Politics Research 37(5): 801-23.

Simpson, William. 2001. QAP: The Quadratic Assignment Procedure. Working paper. http://fmwww.bc.edu/RePEc/nasug2001/simpson.pdf [accessed November 2, 2011].

Smith, Mike, and Mike Beazley. 2000. Progressive Regimes, Partnerships and the Involvement of Local Communities: A Framework for Evaluation. Public Administration 78(4): 855-78.

Steinacker, Annette. 2004. Game-Theoretic Models of Metropolitan Cooperation. In Metropolitan Governance: Conflict, Competition, and Cooperation, edited by Richard C. Feiock, 46-66. Washington, DC: Georgetown University Press.

Visser, James A. 2002. Understanding Local Government Cooperation in Urban Regions: Toward a Cultural Model of Interlocal Relations. American Review of Public Administration 32(1): 40-65.

\section{SUPPORTING INFORMATION}

Additional Supporting Information may be found in the online version of this article:

\section{Figure S2. Policy Networks in the Orlando Metropolitan Areas}

\section{Figure S3. Perceived Competition and Policy Networks}

\section{Figure S4. Perceived Cooperation and Policy Networks}

Please note: Wiley-Blackwell is not responsible for the content or functionality of any supporting materials supplied by the authors. Any queries (other than missing material) should be directed to the corresponding author for the article. 